\title{
Molecular evidence of Zn chelation of the procaspase activating compound B-PAC-1 in B cell lymphoma
}

\author{
Aloke Sarkar ${ }^{1}$, Kumudha Balakrishnan ${ }^{1,3,4}$, Jefferson Chen ${ }^{1}$, Viralkumar Patel $^{1}$, \\ Sattva S. Neelapu ${ }^{2}$, John S. McMurray ${ }^{1,4}$, Varsha Gandhi ${ }^{1,3,4}$ \\ ${ }^{1}$ Department of Experimental Therapeutics, The University of Texas Health Science Center, Houston, Texas, USA \\ ${ }^{2}$ Department of Lymphoma and Myeloma, The University of Texas Health Science Center, Houston, Texas, USA \\ ${ }^{3}$ Department of Leukemia, UT MD Anderson Cancer Center, Houston, Texas, USA \\ ${ }^{4}$ Graduate School of Biomedical Sciences, The University of Texas Health Science Center, Houston, Texas, USA \\ Correspondence to: Varsha Gandhi, e-mail: vgandhi@mdanderson.org \\ Keywords: lymphoma, MCL, pro-caspase-3, Zn-ligands, B-PAC-1 \\ Received: November 13,2015 Accepted: November 17, $2015 \quad$ Published: December 07, 2015
}

\section{ABSTRACT}

The resistance of apoptosis in cancer cells is pivotal for their survival and is typically ruled by mutations or dysregulation of core apoptotic cascade. Mantle cell lymphoma (MCL) is a non-Hodgkin's B-cell malignancy expressing higher antiapoptotic proteins providing survival advantage. B-PAC-1, a procaspase activating compound, induces apoptosis by sequestering $\mathrm{Zn}$ bound to procaspase-3, but the amino acids holding $\mathrm{Zn}$ in Caspase- 3 is not known. Here we show that reintroduction of WT caspase-3 or 7 in Caspase3-7 double knock-out (DKO) mouse embryonic fibroblasts (MEF) promoted B-PAC-1 to induce apoptosis (27-43\%), but not in DKO MEFs or MEFs expressing respective Casp3-7 catalytic mutants (12-13\%). Using caspase- 6 and -9 exosite analysis, we identified and mutated predicted $\mathrm{Zn}$-ligands in caspase-3 (H108A, C148S and E272A) and overexpressed into DKO MEFs. Mutants carrying E272A abrogated Zn-reversal of apoptosis induced by B-PAC-1 via higher XIAP and smac expressions but not in H108A or C148S mutants. Co-immunoprecipitation analysis revealed stronger XIAP-caspase-3 interaction suggesting a novel mechanism of impulsive apoptosis resistance by disrupting predicted $\mathrm{Zn}$-ligands in caspase-3. B-PAC-1 sponsored apoptosis in MCL cell lines (30-73\%) via caspase-3 and PARP cleavages accompanied by loss of Mcl-1 and IAPs including XIAP while $\mathrm{Zn}$ substantially abrogated B-PAC-1-driven apoptosis (18-36\%). In contrary, $\mathrm{Zn}$ is dispensable to inhibit staurosporin, bendamustine, ABT199 or MK206-induced apoptosis. Consistent to cell lines, B-PAC-1 stimulated cell death in primary B-lymphoma cells via caspase-3 cleavage with decline in both Mcl-1 and XIAP. This study underscores the first genetic evidence that B-PAC-1 driven apoptosis is mediated via $\mathrm{Zn}$ chelation.

\section{INTRODUCTION}

Mantle cell lymphoma (MCL) is a fatal B-cell nonHodgkin's malignancy with a tendency to disseminate throughout the body, including lymphoid tissues, bone marrow and peripheral blood there by offering a broad spectrum of clinical, pathological, and biological significance. Cyclin D1 over-expression owing to reciprocal translocation event $\mathrm{t}(11 ; 14)(\mathrm{q} 13 ; \mathrm{q} 32)$ [1], accompanied by constitutively activated PI3K/AKT/ mTOR network, aberrant WNT, Hedgehog and NF$\kappa \mathrm{B}$ pathways are the major forces that drive MCL cell proliferation and survival [2-5]. All these signaling events converge to resistance to apoptosis which in part caused by over-expression of anti-apoptotic Bcl-2 family members including Bcl-2 and Mcl-1 in majority of MCL cells. Given the potential role(s) of pro-apoptotic compounds for treating cancer, incessant efforts are in progress to develop therapeutics that target specific proteins in the apoptotic cascade. Activation of zymogen procaspase-3 (procasp3) to caspase-3 (Casp3) is the hallmark of cell-death pathway and the key "executioner" caspase, catalyzing the hydrolysis of a multitude of protein substrates within the cell [6]. Caspases play a provocative role leading to 
programmed cell death (PCD) and are classified as either initiators or upstream (Casp2, 8 and 9) or executioners or downstream (Casp3, 6 and 7). Executioner caspases are controlled via zymogen activation, in which proteolytic processing by an upstream protease results in the generation of a cleaved, active protein [7]. These caspase zymogens are inherently maintained in a full-length, unprocessed, and inactive dimer before being processed during the onset of PCD. Several targets of apoptotic machinery include genotoxic agents, MDM2-p53 or $\mathrm{B}$-cell receptor pathway inhibitors and $\mathrm{Bcl} 2$ antagonists [8-11] rely on upstream apoptotic cascades yet a few are known to induce directly Casp3-7 bypassing defective upstream apoptotic circuitry. Interestingly, majority of cancer cells including MCL possess relatively higher levels of pro-casp3 [12] and pro-casp7 [13] allowing a rational approach to selectively induce $P C D$ via direct activation of caspases. Therefore targeting cancer cells expressing higher level of pro-casp3 over normal cells would be advantageous. This strategy of direct caspase activation and exterminating upstream regulators of PCD that otherwise help MCL cells to acquire a strong survival advantage is becoming a powerful tool in recent years.

Procaspase-activating compound-1 (PAC-1) was discovered as the first line of procasp3-7 activators along with other PAC-1 derivatives [12, 14-16]. A fluorescent derivative of PAC-1 was found to co-localize within the apoptotic cells expressing Casp3-7 suggest that PAC-1 acts to chelate inhibitory $\mathrm{Zn}$ from procasp3-7 to induce PCD [12, 14-16]. Second generation of PAC-1 derivatives resulted in more potent analog such as B-PAC-1. We describe here the genetic basis of $\mathrm{Zn}$ chelation and caspase activation by B-PAC-1 that directly activate PCD in both MCL cell lines and in primary lymphoma cells with a promise for future therapeutic use.

\section{RESULTS}

\section{B-PAC-1 induced cell death in MCL via Casp3 cleavage: reversal of apoptosis by $\mathrm{Zn}$}

MCL cell lines treated with B-PAC-1 for $24 \mathrm{hr}$ in a dose-dependent manner and their respective $\mathrm{IC}_{50}$ values were determined as $\sim 9.0, \sim 5.0$ or $\sim 7.0 \mu \mathrm{M}$ for Granta-519, Jeko-1 and Mino cells, respectively (Figure 1A). Based on this $\mathrm{IC}_{50}$ value, we selected $10 \mu \mathrm{M}$ for all additional experiments unless specied otherwise. Co-incubation of B-PAC-1 with $\mathrm{Zn}$ rescued cell death in these cells entailing that $\mathrm{Zn}$ plays a role in B-PAC-1-induced PCD (Figure 1B). Treatment with either $\mathrm{Zn}$ or Pac-1a (an inactive derivative of B-PAC-1 10 $\mu \mathrm{M}$ ) failed to accomplish detectable PCD compared to DMSO control (Figure 1C). In contrast, staurosporin-induced apoptosis was not reverted by $\mathrm{Zn}$ (Figure 1C).

Western blot analysis from cells treated with either B-PAC-1 or STS revealed detectable cleavage of
Casp3 substrate PARP (poly ADP ribose polymerase). Interestingly, both Annexin V-PI FACS analysis and protein analysis revealed that ATM deficient [19] Granta-519 was relatively resistant to B-PAC-1-induced PCD compared to ATM proficient Jeko-1 and Mino cells. In contrast, regardless of p53 status, both p53 deficient Jeko-1 and p53 proficient Mino cells [19] were equally sensitive to B-PAC-1 as evidenced by the cleavage of both executioner Casp3 (p17 and p12), Casp7 (p20) and PARP (Figure 1D). Immunoblot assays suggested that multiple anti-apoptotic proteins including IAPs (cIAP1, cIAP-2 and XIAP), Mcl-1 and cyclin D1 levels were reduced following B-PAC-1 treatment. This observation was further supported by direct immunofluorescence analysis from Jeko-1 cells (Figure 1E) indicating B-PAC-1 induced Casp3 cleavage is accompanied by nuclear pycnosis and membrane blebbing. Densitometry analysis (Figure 1F) revealed a significant decline in both XIAP and Mcl-1 protein levels following B-PAC-1 treatment. Consistent with Annexin V-PI FACS data, co-incubation of B-PAC-1 and $\mathrm{Zn}$ also restored XIAP and Mcl-1 proteins, inhibition of Casp3 and Casp7 cleavage and their substrates including PARP and ATM (Figure 1D). Amongst other caspases, B-PAC-1-induced cleavage of initiator Casp9 was inhibited by Zn while Casp6 cleavage was not detected (data not shown) (Figure 1G). The DNA alkylating agent bendamustine, Bcl-2 antagonist ABT199 or pan-AKT inhibitor MK2206 are clinically used for treatment of B-cell malignancies. These agents also induced PCD; however co-incubation of these compounds with $\mathrm{Zn}$ failed to rescue apoptosis. This study indicates that $\mathrm{Zn}$ induced reversal of PCD is B-PAC-1-specific (Figure 1H).

\section{Casp3-7 DKO MEFs were resistant to B-PAC-1- driven apoptosis}

Further explication of the role of Casp3 and Casp7 during B-PAC-1-induced apoptosis was evaluated in a series of MEF cell lines. While B-PAC-1 (10 $\mu \mathrm{M}$ for $24 \mathrm{hr})$ sensitized WT MEF (Casp3-7+/+) to PCD, Zn (100nM for $24 \mathrm{hr}$ ), mostly inhibited B-PAC-1 action. In contrast, MEF cells lacking a single allele for both Casp3 and -7 (Casp3$7+/-)$ were less sensitive to B-PAC-1-driven apoptosis compared with WT MEF. As expected B-PAC-1 failed to sensitize DKO MEF cells to induce PCD, suggesting dependence of Casp3 and -7 for final execution of PCD by B-PAC-1 (Figure 2A and 2B).

Stable reintroduction of WT Casp3 into DKO MEF cells significantly sensitized B-PAC-1 induced PCD, while Casp3 catalytic mutant (Casp3C163A) blunted the effect of B-PAC-1 suggesting that Casp3 with an active site cysteine in the nucleophilic attack site is required for targeting B-PAC-1 to induce PCD. Although less sensitive, B-PAC-1 still induced PCD in DKO MEF cells stably transfected with WT Casp7 but not in Casp7 catalytic mutant (Casp7C186A) reconfirming that both Casp3 


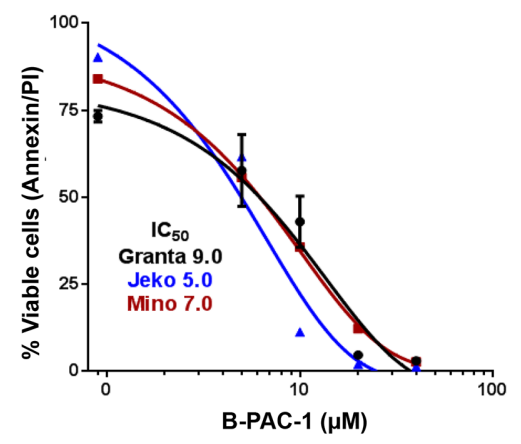

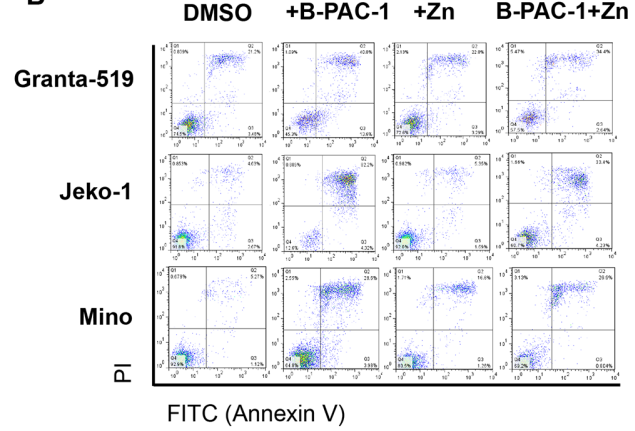

C
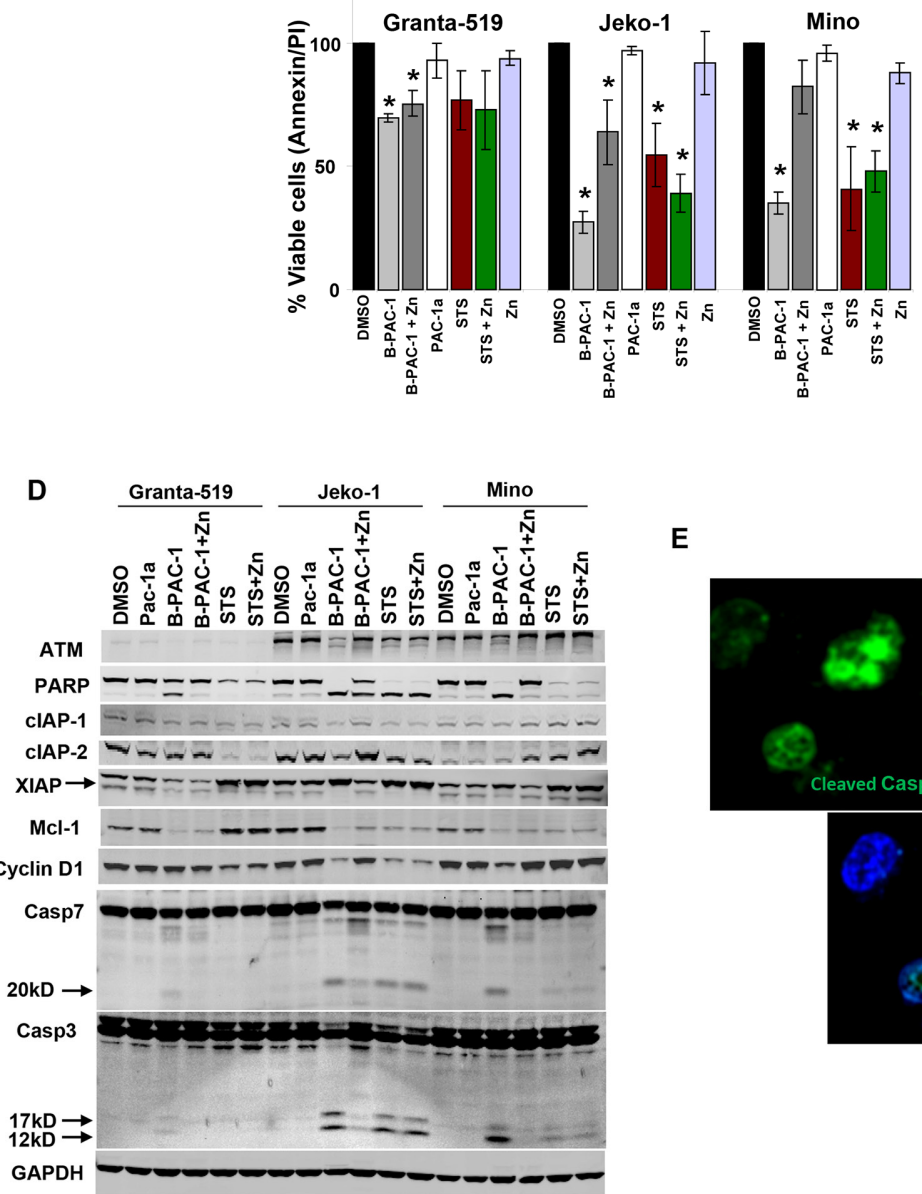

$\mathrm{E}$
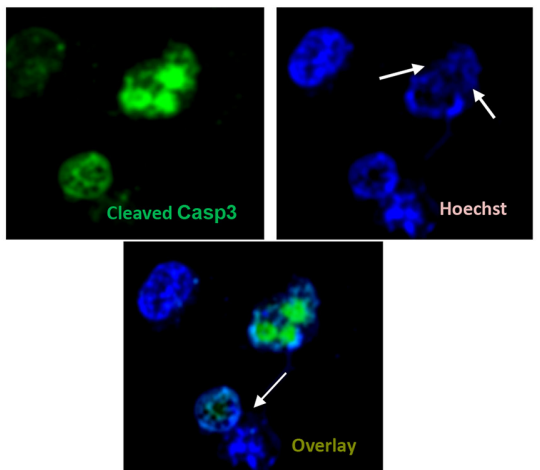

Figure 1: B-PAC-1 induce cell death in MCL cell lines by activating Casp3. A. Dose dependent cell death by B-PAC-1 in MCL cell lines. Granta-519, Jeko-1 and Mino cells were incubated with increasing concentration of B-PAC-1 for 24 hr, stained with Annexin V-PI and acquired in FACS caliber for cell death analysis. Their respective $\mathrm{IC}_{50}$ value was determined as shown in the inset. B. FACS analysis showing differential cell death induced by B-PAC-1 (10 $\mu \mathrm{M}, 24 \mathrm{hr})$ with or without $\mathrm{Zn}$ in Granta-519, Jeko-1 or Mino cells. C. Annexin V-PI FACS analysis of B-PAC-1 induced cell death (Granta-519; ${ }^{*} p<0.0001$; Jeko-1; ${ }^{*} p<0.0001$ and Mino; ${ }^{*} p<0.0001$ ) or inhibition by Zn (Granta-519; ${ }^{*} p<0.007$; Jeko-1; $\left.{ }^{*} p<0.035\right)(n=5$; Mean \pm SE) as described in B. Pac-1a, was used as negative control while staurosporine (STS; $100 \mathrm{nM})$ was used as positive control $(n=3 * p<0.03-0.004$ in Granta-519; $* p<0.03-0.002$ in Jeko-1 or * $p<0.020$ 0.003 in Mino cells compared with DMSO control. D. Western blot analysis of protein extracts (30 $\mu$ g) from Granta-519, Jeko-1 and Mino cells treated with indicated compounds for $24 \mathrm{hr}$ showing cleavage of Casp3 and Casp7 by B-PAC-1 and STS accompanied by cleavage of both Casp3 substrates ATM and PARP and corresponding loss of XIAP, Mcl-1, cIAP-1 and cIAP-2 proteins. Treatment with inactive Pac1a $(10 \mu \mathrm{M})$ was used as negative control and $\mathrm{Zn}$ was utilized to abrogate B-PAC-1 induced PCD. GAPDH was used for loading control. Identical blots were either reprobed or cut in strips and separately probed with antibodies for indicated proteins. E. Immunofluorescence analysis of Jeko-1 cells treated with B-PAC-1 for $24 \mathrm{hr}$ showing Casp3 cleavage is accompanied by nucleosomal pyknosis. Arrows indicate nuclear pyknosis in cleaved Casp3 expressing cells. 

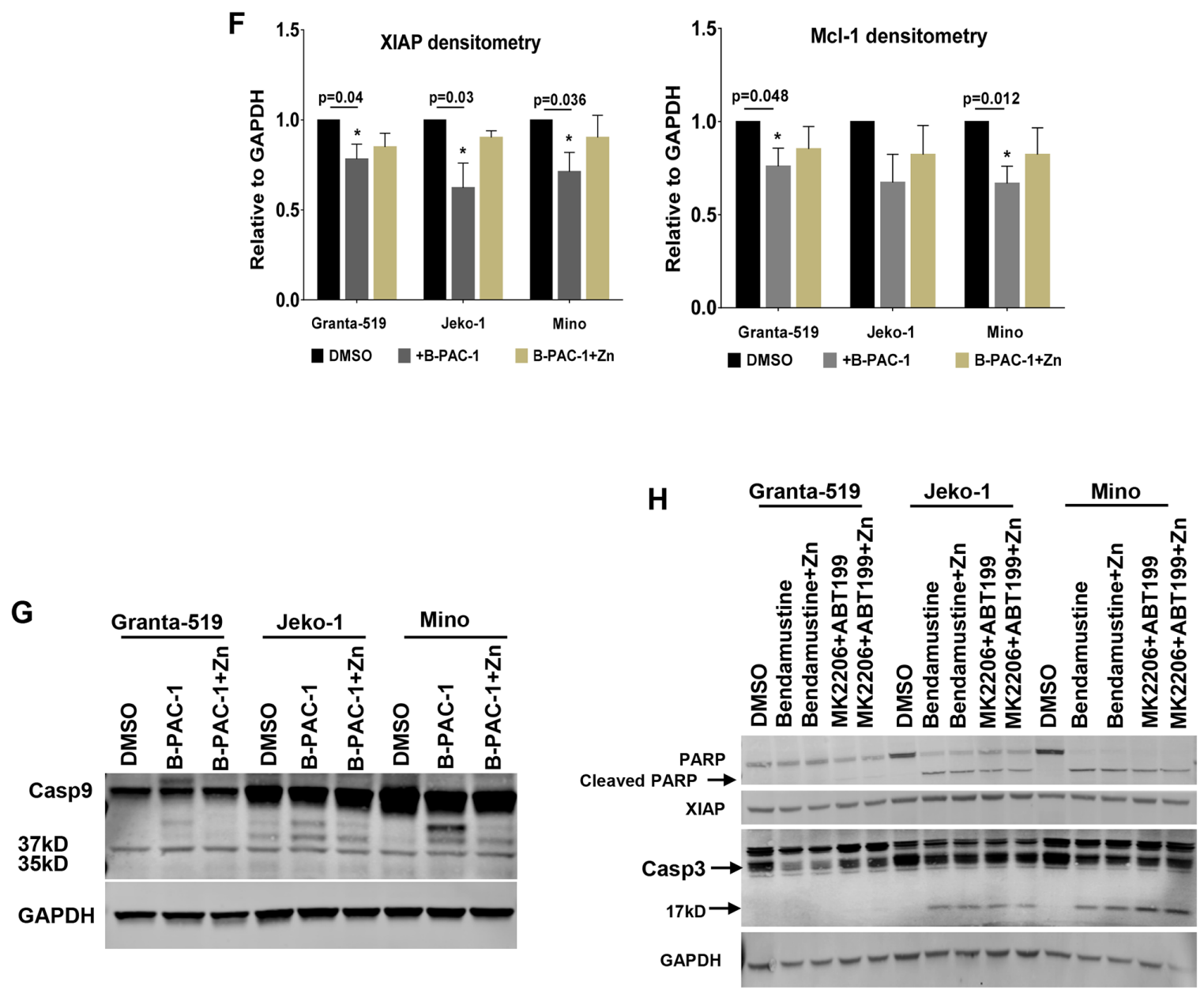

Figure 1: (Continued) F. Densitometry analysis $(n=4$; Mean \pm SE) showing loss of anti-apoptotic proteins XIAP and Mcl-1 following treatment with B-PAC-1 and $\mathrm{Zn}$ in Granta-519, Jeko-1 and Mino cells. *Significant difference from control. G. Western blot analysis $(30 \mu \mathrm{g})$ of protein extracts from Granta-519, Jeko-1 and Mino cells showing cleavage of Casp9. Arrows indicating 37 and $35 \mathrm{kD}$ cleaved bands. GAPDH was used for loading control. H. Western blot $(30 \mu \mathrm{g})$ analysis showing cleavage of Casp3 and PARP and loss of XIAP in MCL cell lines treated with Bendamustine $(30 \mu \mathrm{M})$ or a combination of ABT199 $(20 \mu \mathrm{M})$ and MK2206 $(5 \mu \mathrm{M})$ for $24 \mathrm{hr}$ in presence or absence of Zn (100nM). GAPDH was used for loading control.

and -7 are important watchdogs for the final execution of B-PAC-1-induced apoptosis (Figure 2A and 2B). Western blot analysis revealed B-PAC-1 elicit depletion of full length PARP, Mcl-1 and XIAP levels accompanied by cleavage of Casp3 (17 and $12 \mathrm{KD}$ ) or Casp7 (20kD) in both WT and in Casp3-7+/- MEF cells. AnnexinV-PI FACS analysis reconfirmed B-PAC-1 driven PCD into DKO MEF cells carrying WT Casp3, Casp7 or Casp3-7+/but not in DKO MEF cells carrying respective catalytic mutant versions (Figure 2C).

\section{Identification of the predicted $\mathrm{Zn}$-binding amino acids in Casp3}

Active Casp3 is a dimer of two cleaved procaspases as illustrated in Figure $3 \mathrm{~A}$ and its catalytic activity is inhibited by $\mathrm{Zn}$ [20-21]. A recent report showed that three atoms of zinc bind to Casp3. Presuming that one $\mathrm{Zn}$ binds to the catalytic site, a common trait for all cysteine proteases, it was hypothesized that the other two zinc atoms may modulate catalytic activity, as reported for Casp6 and Casp9 [22]. The locations of the two non-catalytic zinc binding sites in Casp3 are currently unknown. Velaquez-Delgado and Hardy [23] recently reported that Casp6 binds two $\mathrm{Zn}$ atoms and using X-ray crystallography studies determined the binding site of the second metal ion, the Casp6 exosite. Occupation of this site by $\mathrm{Zn}$ has an inhibitory effect on the catalytic activity. Casp9 binds two $\mathrm{Zn}$ ions and site directed mutagenesis, determined the location of the second ion, the Casp9 exosite [22]. Using sequence and structural alignment, Velaquez-Delgado and Hardy [23] reported that in Casp3, the Casp6 exosite, (thereafter referred to as exosite-6), is comprised of Ser36, Glu272, and Tyr274 (Figure 3B). As in Casp6, with respect to the location of the catalytic site, these amino acids reside at the distal end of an $\alpha$-helix, as shown in Casp3 crystal structure (PDBID 1PAU) [24-26]. This exosite does not 
contain the canonical zinc binding residues cysteine and histidine, but serine, glutamic acid, and tyrosine, and nearby Glu231 could potentially form a unique chelation site. Further, these residues could participate in intraand inter-subunit interactions that could impact activity (Figure 3C). In Casp3, the Casp9 exosite, (exosite-9), is composed of His108, Ser113, Phe114, and Cys148. Of these, the X-ray structures of Casp3 show that the histidine and cysteine residues are positioned to chelate zinc and this site is also located distal from the catalytic site (Figure 3D). This site is highly conserved in all caspases [23]. To determine if either of these potential exosites has a bearing on B-PAC-1-driven activity of Casp3, mutations of key residues were introduced. In exosite-6, Glu272 was mutated to alanine. In exosite-9,
His 108 and Cys 148 were mutated to alanine and serine respectively.

A series of Flag-tagged Casp3 constructs harboring mutations were generated into the human Casp3 ORF and sequence verified as shown in Figure 4A. All these constructs were sub-cloned into a $\mathrm{C}$ terminal 3XFlagepitope tagged vector and were stably transected into DKO MEF cells. Both B-PAC-1 and $\mathrm{Zn} \mathrm{IC}_{50}$ values were titrated using WT Casp3 transfected DKO MEF cells (Supplemental information S1 and S2) and used for the entire experiment. While DKO MEF cells carrying vector alone failed to induce PCD, (Figure 4B), WT Casp3 transfected cells were sensitized by B-PAC-1 induced PCD and $\mathrm{Zn}$ significantly reverted apoptosis. Interestingly, cells carrying Casp3 mutants encountered a relative resistance

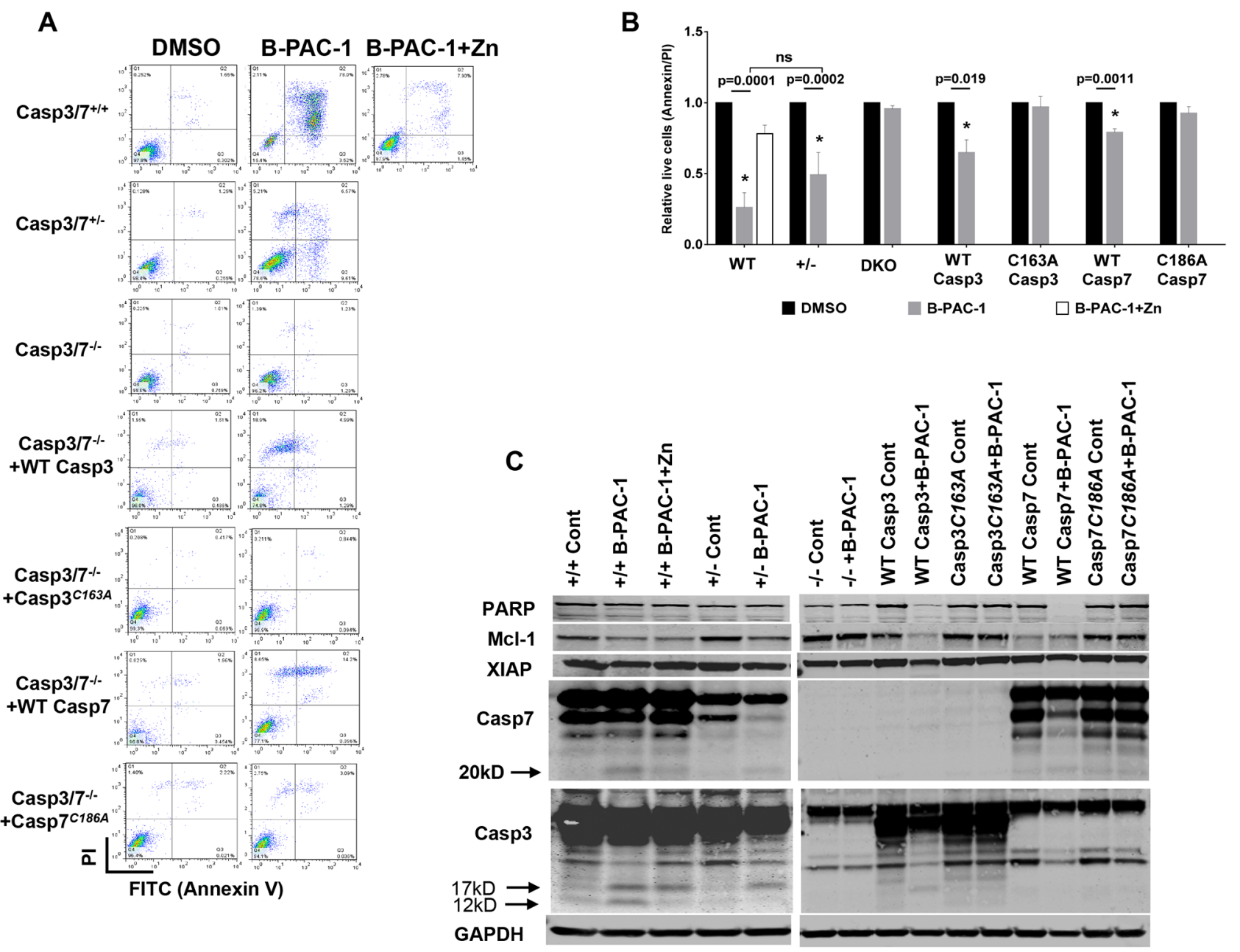

Figure 2: Casapse3/7 DKO MEF cells are resistant to B-PAC-1 induced cell death. A. Annexin V-PI FACS analysis of B-PAC-1 induced cell death in the indicated MEF cells with either a WT Casp3 or Casp7 or MEF cells carrying a mutation in the respective catalytic sites. DMSO was used as control. B. Cells were treated in triplicate as in 2A and relative live cells (Annexin V-PI) were plotted as percent of control mean $(n=3 \pm \mathrm{SE})$. *Significant difference from control. C. Immunoblot analysis of protein isolated from indicated cells before and after treatment with B-PAC-1 (10 $\mu \mathrm{M}$ for $24 \mathrm{hr}$ ). For PARP, XIAP and Mcl-1, $50 \mu \mathrm{g}$ protein was used while $250 \mu \mathrm{g}$ was loaded for Casp3 and Casp7. GAPDH (50 $\mu \mathrm{g}$ from same extracts) was used for loading control. 
to B-PAC-1-induced PCD compared with WT Casp3. B-PAC-1 induced PCD was significantly reversed by $\mathrm{Zn}$ in both $\mathrm{H} 108 \mathrm{~A}$ and $\mathrm{C} 148 \mathrm{~S}$ single mutants but failed to rescue in E272A single mutant or in double and triple mutants harboring E272A when compared with WT Casp3 (Figure 4C). Western blot analysis revealed B-PAC-1 driven PCD was accompanied by loss of full length PARP and XIAP and Casp3 cleavage (p17) in WT and Zn-Casp3 mutants (Figure 4D). Surprisingly, majority of Zn-Casp3 mutants expressed a relatively higher basal XIAP in presence of B-PAC-1 or B-PAC-1+Zn when normalized with cleaved Casp3 (p17) (Figure 4E). Neither basal pro-casp3 nor B-PAC-1 induced cleaved Casp3 (p17) fragment were altered in these clones. This data advocates a possible mechanism of resistance to spontaneous cleavage of apoptotic protease in these mutants via up-regulation of XIAP protein.

\section{Elevated Casp3-XIAP physical interaction and higher smac expression: inhibition of spontaneous apoptosis in DKO MEF cells carrying mutant Casp3}

Having observed a relatively higher basal XIAP expression in majority of Zn-Casp3 mutants, we next tested Casp3-XIAP physical interaction in the mutant clones. Based on exosite cluster analysis, we hypothesized that by dismantling $\mathrm{Zn}$ ligands in Casp3 would spontaneously induce PCD. However, we could not detect any spontaneous PCD in these mutant clones. Immunoprecipitation analysis revealed a relatively higher Casp3-XIAP physical interaction in MEF cells carrying E272A mutation compared with WT Casp3 (Figure 5A). Alternatively, transient transfection assay into HEK293 cells co-transfected with vector, Casp3 (WT and all E272A
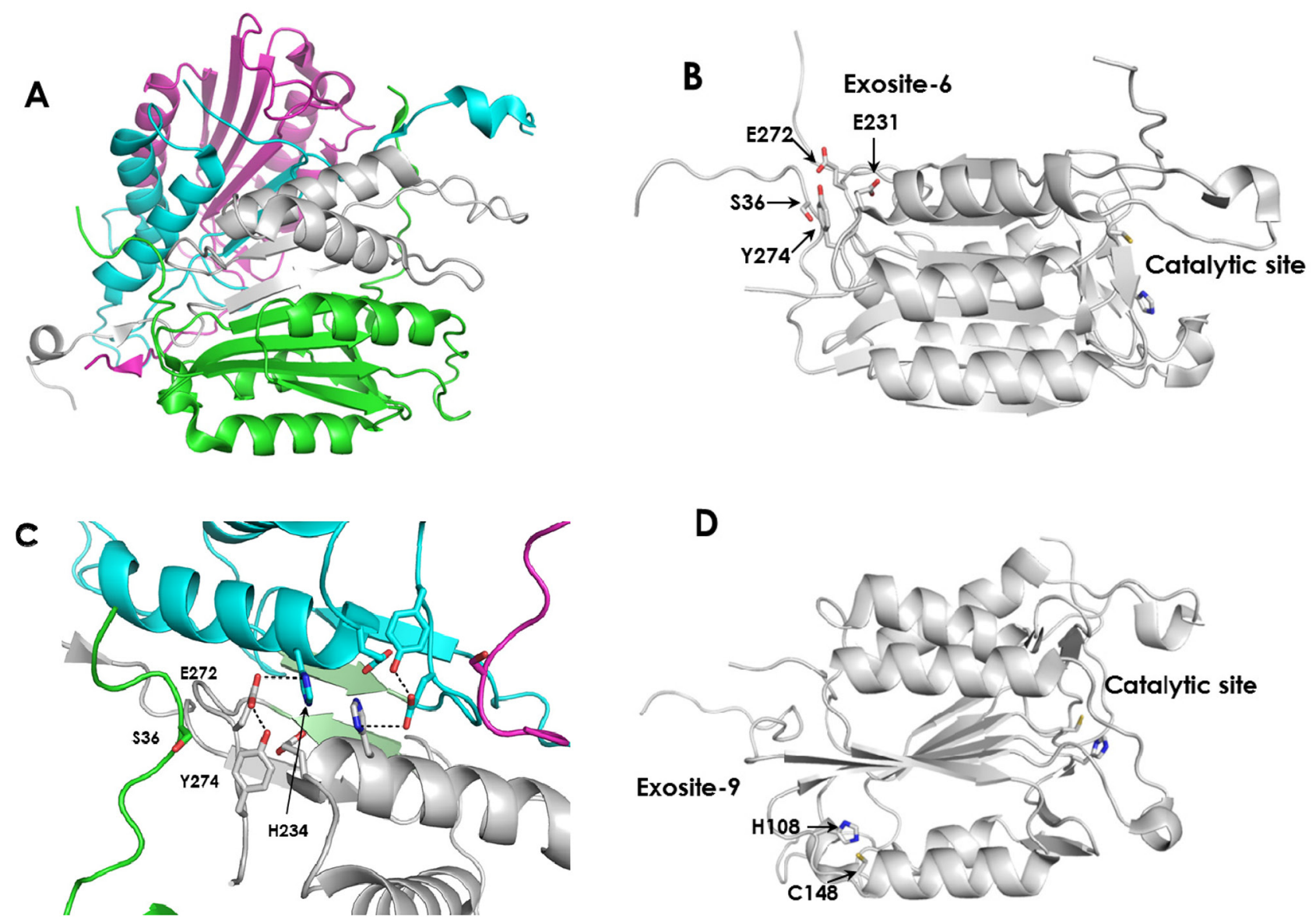

Figure 3: The structure of active Casp3 and the locations of potential Zn binding sites. A. Casp3 as a dimer of heterodimers. The large and small subunits of one molecule of active Casp3 are colored green and white respectively. The corresponding subunits of the second Casp3 are colored magenta and cyan, respectively. (From PDBID 1I30). B. Exosite-6 is located distal from the catalytic site. C. Intra-subunit and inter-subunit interactions of E272 in exosite-6. The small subunit of the first Casp3 protein is colored white and the region of the large subunit containing Ser36 is colored green. The small subunit of the second Casp3 protein is colored cyan and the region of the large subunit containing Ser36 is colored magenta. Interacting $\beta$-sheets 264-267 from the opposing small subunits are colored light green. Hydrogen bonds between Glu272 and Tyr274 are depicted by black dashed lines. Potential inter-subunit hydrogen bonds between Glu272 and His 234 are also indicated by black dashed lines. (from PDBID 1I30). D. Exosite-9 is located distal from the active site. Panels B and $\mathrm{C}$ were derived from PDBID 2J30. 

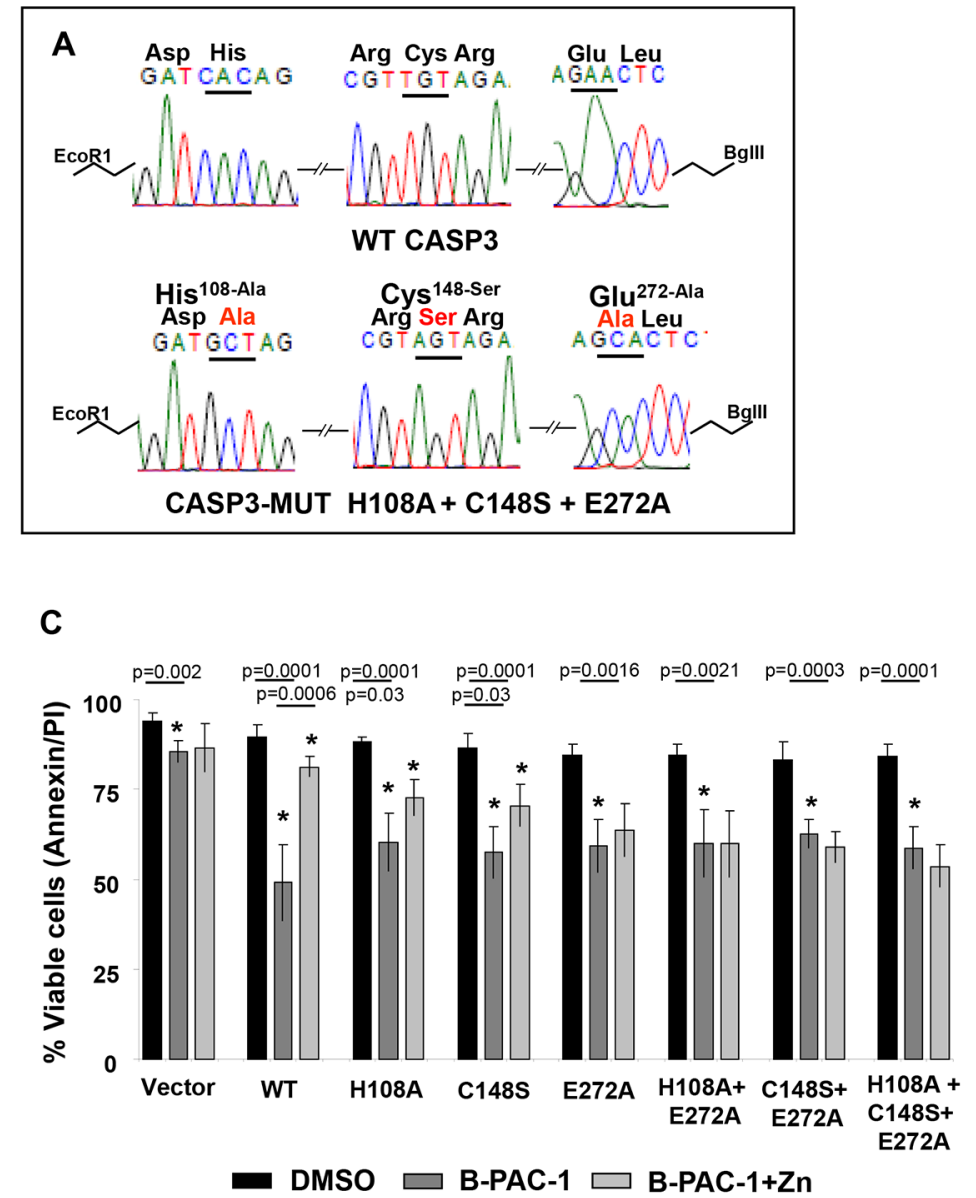
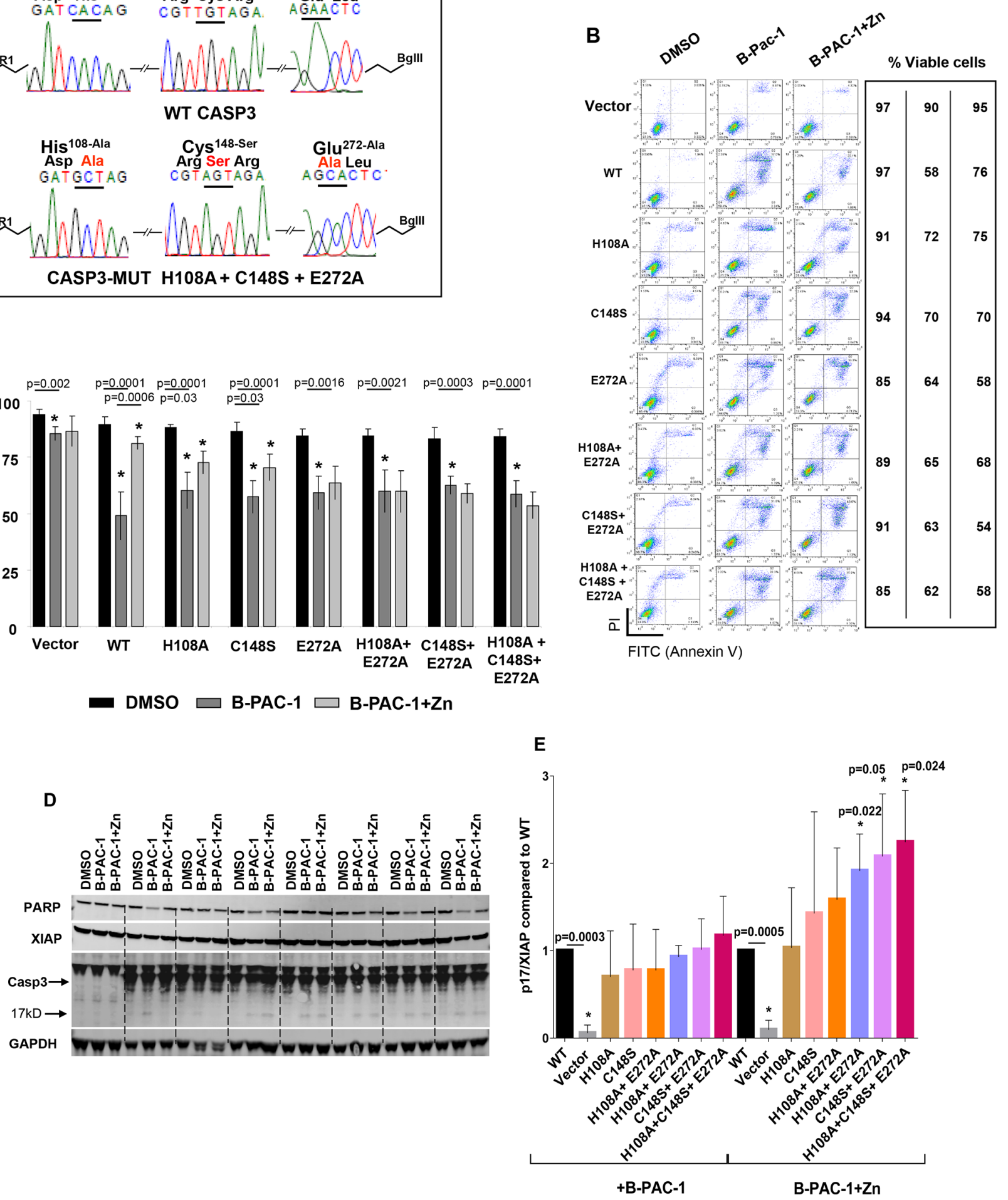

Figure 4: Mutation of predicted $\mathrm{Zn}$ binding regions in Casp3 preprotein abolishes $\mathrm{Zn}$ reversal of apoptosis induced by B-PAC-1 in MEF cells. A. Nucleotide and amino acid sequence analysis showing WT and mutated Zn binding regions of Casp3 protein. B. Annexin V-PI FACS analysis showing cell death induced by B-PAC-1 (15 $\mu \mathrm{M}$ for $24 \mathrm{hr}$ ) with or without Zn (90 $\mu \mathrm{M}$ for $24 \mathrm{hr})$ in vector control Casp3-7 DKO, WT Casp3 or in MEFs stably transected with Casp3 constructs harboring mutated Zn binding amino acids. C. MEFs were treated as in $\mathrm{B}$ and mean $(n=5 ; \pm \mathrm{SE})$ values relative to DMSO control are plotted. *Significant difference from control. D. Immunoblot analysis of total protein isolated from indicated cells showing cleavage of Casp3; (arrow indicates cleaved Casp3 band), XIAP, and full length PARP. GAPDH (250 $\mu \mathrm{g}$ from similar extracts) was probed for loading control. E. Experiment was conducted as in D showing mean $(n=3 \pm$ SEM) densitometry analysis of cleaved Casp3 (p17) and XIAP ratios compared to WT Casp3 transfected MEF cells. *Significant difference from control. 

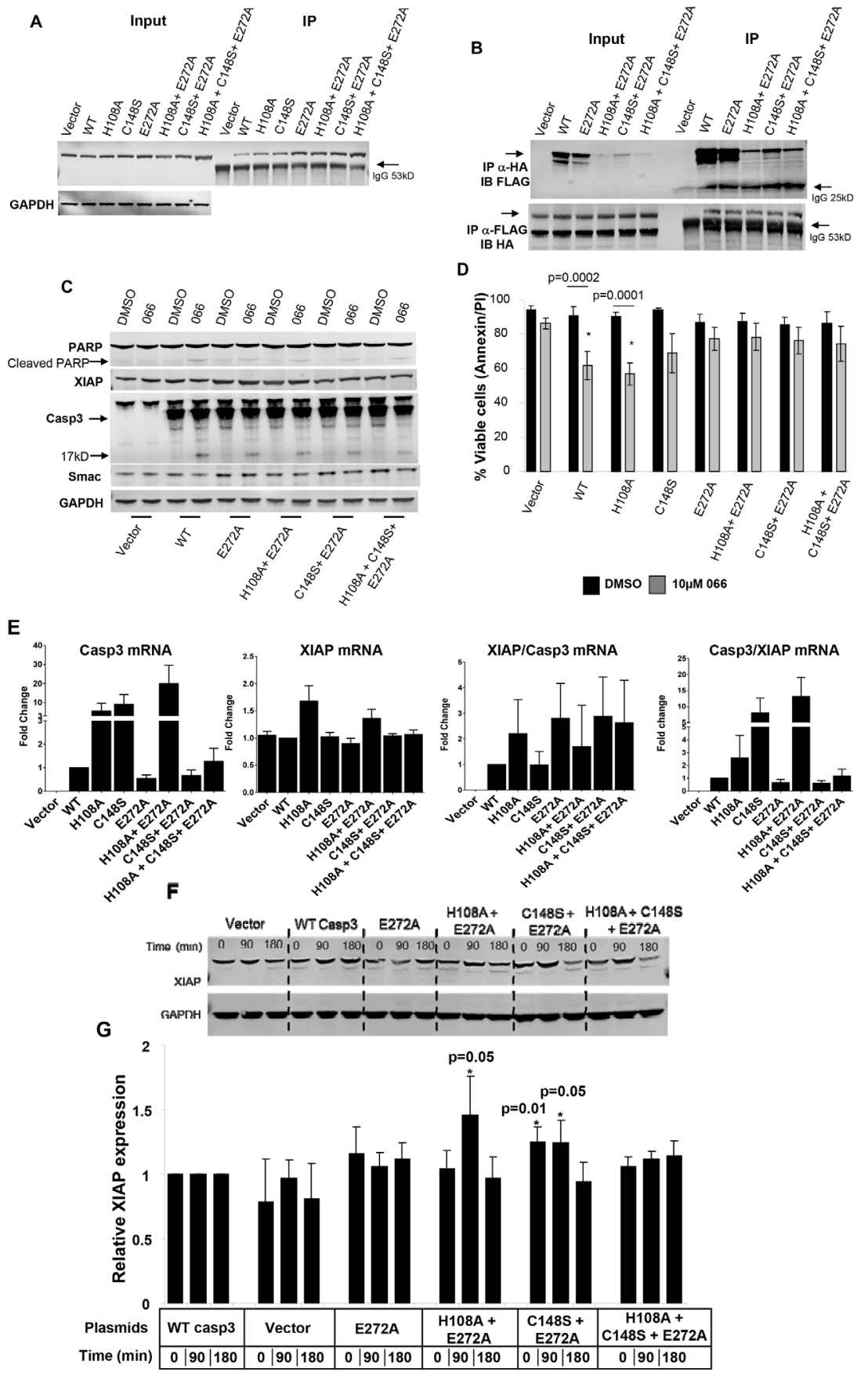

Figure 5: Enhanced Casp3-XIAP physical interaction in Casp3-Zn mutants. A. Immunoprecipitation analysis (3000 $\mu$ g) with anti-FLAG antibody showing endogenous XIAP levels in MEF cells engineered with WT and Casp3 mutants. $50 \mu \mathrm{g}$ total extract was loaded as input control (left panel). Arrow indicates IgG heavy chain. B. Co-immunoprecipitation analysis using HEK293 cells transiently transfected with HA-XIAP and indicated Casp3 plasmids. $50 \mu \mathrm{g}$ total extract was loaded as input control (left panel). Immunoprecipitated proteins were either probed with anti-FLAG antibody (upper panel; showing amount of Casp3 bound to XIAP) or anti-HA antibody showing amount of XIAP bound to Casp3 (lower panel). Arrow indicates IgG light $(\sim 25 \mathrm{kD}$ upper panel) or heavy ( $\sim 53 \mathrm{kD}$ lower panel) chains. C. Immunoblot analysis of total protein isolated from stably transfected MEF cells with indicated plasmids showing smac mimetic

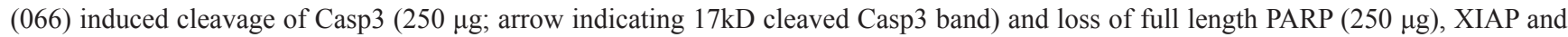
smac $(50 \mu \mathrm{g})$ protein expressions. GAPDH (50 $\mu \mathrm{g}$ from similar extracts) was probed for loading control. D. Annexin V-PI FACS analysis induced by smac mimetic (066) $(n=5$; Mean $\pm \mathrm{SE})$ showing relative live cell in the indicated cell clones compared with individual DMSO controls. *Significant difference from control. E. Casp3 and XIAP mRNA expressions and their relative ratios in stably transfected MEF cells expressing vector, WT or Zn-Casp3 mutants. Cells were treated and processed for real-time RT-PCR assays. Data are mean $\pm \mathrm{SE}$ $(n=3)$. F. Time course of cycloheximide (CHX) treatment in MEF cells showing XIAP protein expression (upper panel) in control, WT and Zn-Casp3 mutants. GAPDH was probed for loading control. G. Densitometry analysis ( $n=5$; Mean \pm SE) showing relative XIAP protein levels in vector control, single (E272A), double (H108A+E272A and C148S+E271A) and triple (H108A+C148S+E272A) mutants compared with WT Casp3 transfected cells at identical time points. *Significant difference from control. 
harboring mutants) and HA-XIAP constructs demonstrated that an increased Casp3-XIAP physical interaction in majority of E272A harboring mutants compared with WT Casp3 transfected cells (Figure 5B). These data substantiate that mutation in predicted Zn-Casp3 amino acids reciprocally inhibit spontaneous $\mathrm{PCD}$ via acquiring an increased affinity of XIAP-Casp3 physical interaction.

Owing to stronger Casp3-XIAP complex in these mutants, we next hypothesized that perhaps more Smac mimetic is required in order to dismantle Casp3-XIAP interaction in order to induce PCD. MEF cells carrying WT Casp3 were titrated to determine $\mathrm{IC}_{50}$ value of 066 (Supplemental information S3). MEF cells carrying WT or Zn-Casp3 mutants were identically treated with 066 and their viability was determined by AnnexinV-PI FACS analysis (SI Information S4). Western blot analysis revealed 066-induced PCD was more pronounced in WT
Casp3 carrying MEF cells accompanied by cleavage of PARP, loss of XIAP and smac levels and Casp3 (p17) cleavage compared to Zn-Casp3 mutants (Figure 5C and SI Information S5) while majority of these mutants retained relatively higher smac expression in identical condition. AnnexinV-PI FACS analysis reconfirmed that 066 significantly induced PCD $(p<0.0001-0.0002)$ in both WT and H108A mutant, while C148S and mutants carrying E272A were resistant to 066. This data prompted us to study real time RT-PCR analysis of Casp3 and XIAP mRNA levels in these clones. A relatively higher Casp3 mRNA expression was observed in H108A, C148S and in C148S+E272A double mutant compared with WT (Figure 5E and Supplemental information S5). In contrast, XIAP expressions remained unchanged in majority of clones except in $\mathrm{H} 108 \mathrm{~A}$ and $\mathrm{C} 148 \mathrm{~S}+\mathrm{E} 272 \mathrm{~A}$ double mutants. However, the ratio of XIAP/Casp3 remained higher in
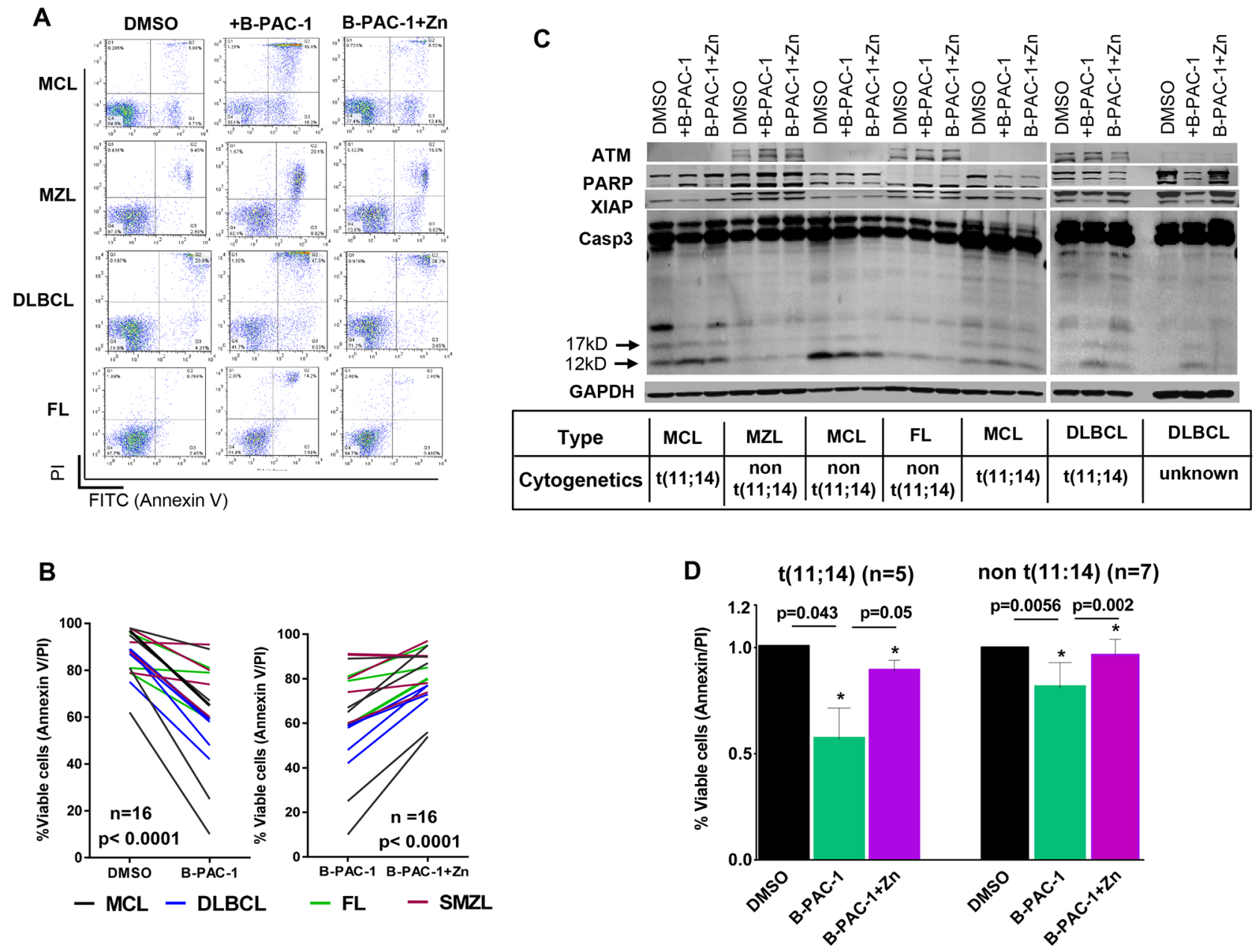

Figure 6: Primary lymphoma cells from patients are sensitive to B-PAC-1 induced cell death. A. Annexin V-PI FACS analysis showing multiple B-cell primary lymphoma samples treated with B-PAC-1 (10 $\mu \mathrm{M}$ for $24 \mathrm{hr})$ with or without concomitant $\mathrm{Zn}$ incubation. B. B-PAC-1-mediated cell death and reversal of apoptosis by Zn in primary lymphomas were plotted $(n=16 ; p<0.0001)$. C. Immunoblot analysis $(30 \mu \mathrm{g})$ of a panel of primary lymphoma samples showing B-PAC-1 induced cell death or Zn inhibition of apoptosis as shown by Casp3 cleavage (p12 and p17 bands). Membrane was cut and fragments were probed with ATM, PARP and XIAP. GAPDH was used as loading control. D. Cell death induction by B-PAC-1 or reversal of apoptosis by Zn in MCL primary samples harboring $\mathrm{t}(11: 14)(n$ $=5)$ and in non $\mathrm{t}(11 ; 14)$ cytogenetics $(n=7)$. DMSO treatment was used as control. *Significant difference from control. 
Table 1: Patient characteristics and B-PAC-1 induced cell death

\begin{tabular}{|c|c|c|c|c|c|c|c|c|c|}
\hline & & & & & & & \multicolumn{3}{|c|}{$\%$ viable cells } \\
\hline Pt \# & $\begin{array}{l}\text { Type of } \\
\text { Disease }\end{array}$ & Age (yrs) & Gender & Cytogenetics & Cytogenetics & $\begin{array}{l}\text { Additional } \\
\text { information }\end{array}$ & DMSO & B-PAC-1 & $\begin{array}{l}\text { B-PAC-1 } \\
\quad+\mathrm{Zn}\end{array}$ \\
\hline 1 & MCL & 60 & $\mathrm{~F}$ & $\mathrm{t}(11 ; 14)$ & Complex & $\begin{array}{l}\text { At initial } \\
\text { diagnosis }\end{array}$ & 97 & 65 & 95 \\
\hline 2 & MCL & 60 & $\mathrm{~F}$ & $\mathrm{t}(11 ; 14)$ & Complex & $\begin{array}{l}\text { At initial } \\
\text { diagnosis }\end{array}$ & 95 & 67 & 87 \\
\hline 3 & MCL & 43 & M & $\mathrm{t}(11 ; 14)$ & Complex & Refractory & 62 & 10 & 54 \\
\hline 4 & MCL* & 60 & M & $\mathrm{t}(11 ; 14)$ & $\begin{array}{c}6 \mathrm{q}-,+11 \mathrm{q} 22.3 \\
(\mathrm{ATM} \times 3), 13 \mathrm{q}-\end{array}$ & $\begin{array}{l}5 \text { months } \\
\text { after initial } \\
\text { Dx }\end{array}$ & 38 & 12 & 34 \\
\hline 5 & MCL & Unkn & Unkn & Unkn & Unknown & Unknown & 98 & 89 & 90 \\
\hline 6 & MCL & 57 & M & $\mathrm{t}(11 ; 14)$ & $\begin{array}{c}\text { Diploid male } \\
\text { karyotype } \\
\text { 46,XY }\end{array}$ & $\begin{array}{l}\text { At initial } \\
\text { diagnosis }\end{array}$ & 81 & 25 & 56 \\
\hline 7 & MCL* & 61 & $\mathrm{~F}$ & $\mathrm{t}(11 ; 14)$ & Complex & $\begin{array}{l}\text { Relapsed and } \\
\text { Refractory }\end{array}$ & 53 & 33 & 42 \\
\hline 8 & SMZL & 73 & $\mathrm{~F}$ & $\mathrm{t}(11 ; 14)$ & Complex & Refractory & 92 & 91 & 90 \\
\hline 9 & SMZL & 75 & M & Normal & $\begin{array}{l}\text { Pseudodiploid } \\
\text { clone } \\
46, X Y, \operatorname{del}(7) \\
\text { (q22q34) [15] }\end{array}$ & $\begin{array}{c}\text { Dx in } \\
\text { 2008; on } \\
\text { observation }\end{array}$ & 88 & 60 & 74 \\
\hline 10 & MZL & 39 & M & Normal & $\begin{array}{l}\text { Diploid male } \\
\text { karyotype } \\
\text { 46,XY [20] }\end{array}$ & $\begin{array}{c}\text { Dx in } \\
\text { 2010; on } \\
\text { observation }\end{array}$ & 98 & 80 & 97 \\
\hline 11 & MZL & 74 & M & Normal & $\begin{array}{c}\text { Hyperdiploid } \\
\text { male 47,XY,+Y } \\
{[1]}\end{array}$ & $\begin{array}{l}\text { At initial } \\
\text { diagnosis }\end{array}$ & 79 & 74 & 78 \\
\hline 12 & MZL* & 71 & $\mathrm{~F}$ & Normal & Complex & Refractory & 5 & 15 & 22 \\
\hline 13 & DLBCL & 59 & M & Normal & $t(14 ; 18)$ & Refractory & 87 & 58 & 77 \\
\hline 14 & DLBCL & 47 & $\mathrm{~F}$ & Unkn & Unknown & Refractory & 89 & 48 & 77 \\
\hline 15 & DLBCL & 72 & $\mathrm{~F}$ & Unkn & Unknown & $\begin{array}{l}\text { Relapsed and } \\
\text { Refractory }\end{array}$ & 75 & 42 & 71 \\
\hline 16 & DLBCL & 67 & M & Unkn & $\begin{array}{c}\text { Diploid } \\
\text { with random } \\
\text { chromosome } \\
\text { loss } \\
40 \sim 43, \mathrm{XY}[\mathrm{cp} 4]\end{array}$ & $\begin{array}{l}\text { At initial } \\
\text { diagnosis }\end{array}$ & 89 & 59 & 73 \\
\hline 17 & FL & 57 & $\mathrm{~F}$ & Normal & $\begin{array}{c}\text { Diploid female } \\
\text { karyotype } \\
46, X X[20]\end{array}$ & $\begin{array}{c}\text { Relapsed and } \\
\text { Refractory }\end{array}$ & 81 & 79 & 85 \\
\hline
\end{tabular}




\begin{tabular}{|c|c|c|c|c|c|c|c|c|c|}
\hline \multirow[b]{2}{*}{ Pt \# } & \multirow[b]{2}{*}{$\begin{array}{l}\text { Type of } \\
\text { Disease }\end{array}$} & \multirow[b]{2}{*}{ Age (yrs) } & \multirow[b]{2}{*}{ Gender } & \multirow[b]{2}{*}{ Cytogenetics } & \multirow[b]{2}{*}{ Cytogenetics } & \multirow[b]{2}{*}{$\begin{array}{c}\text { Additional } \\
\text { information }\end{array}$} & \multicolumn{3}{|c|}{$\%$ viable cells } \\
\hline & & & & & & & DMSO & B-PAC-1 & $\begin{array}{c}\text { B-PAC-1 } \\
+ \text { Zn }\end{array}$ \\
\hline 18 & FL & 57 & $\mathrm{~F}$ & Normal & $\begin{array}{c}\text { Diploid female } \\
\text { karyotype } \\
46, \mathrm{XX}[20]\end{array}$ & $\begin{array}{l}\text { Relapsed and } \\
\text { Refractory }\end{array}$ & 96 & 81 & 95 \\
\hline 19 & FL & 68 & $\mathrm{M}$ & Normal & $\begin{array}{c}\text { Diploid male } \\
\text { karyotype } \\
46, X Y[20]\end{array}$ & $\begin{array}{l}\text { At initial } \\
\text { diagnosis }\end{array}$ & 79 & 59 & 80 \\
\hline
\end{tabular}

*Due to low viability of cells at collection, these samples were tested with B-PAC-1 and Zn but not included in analysis; Unkn, unknown;

these mutant clones compared with MEFs carrying WT Casp3. This observation supports protein expressions in transient transfection assay with either higher XIAP or lower Casp3 expressions leading to an increased affinity of XIAP-Casp3 physical interaction (Figure 5B). Although none of these mRNA expression data were significant, we predicted a possible stability of XIAP protein in these clones. Cycloheximide treatment in these clones followed by protein and densitometry analysis revealed a relatively higher XIAP stability in the double mutants harboring E272A compared with WT Casp3 (Figure 5F). Collectively, these studies demand a possible novel mechanism of resistance in these clones averting spontaneous PCD following mutation in the predicted Zn ligands in Casp3 via higher XIAP-Casp3 physical interaction, higher XIAP and smac expressions and XIAP stability.

\section{B-PAC-1 induces apoptosis in primary B-cell lymphoma cells}

Primary lymphoma cells from 19 patients including $\operatorname{MCL}(n=7)$, MZL $(n=5)$, DLBCL $(n=4)$ and FL $(n=$ 3 ) were tested (Table 1). B-PAC-1-induced PCD was a common feature in all these samples regardless of their subtype while co-incubation with $\mathrm{Zn}$ resulted in significant inhibition of $\mathrm{PCD}$ (Figure 6A and 6B). Amongst different lymphomas (Figure 6B) MCL and DLBCL subtypes were more sensitive than MZL and FL samples. Western blot analysis showed B-PAC-1-induced cleavage of Casp3 and PARP together amid loss of XIAP (Figure 6C). In several primary cells, ATM protein expression was undetectable; a common feature in MCL [27]. Collectively, B-PAC-1 stimulates PCD in primary lymphomas regardless of ATM status (Figure 6D) and this was partially reverted by $\mathrm{Zn}$ addition.

\section{DISCUSSION}

The treatment of MCL is an enormous challenge and is characterized by an aggressive clinical course and inevitable development of relapsed/refractory disease with a median overall survival time of only 3-5 years [28-30]. While immunotherapy with rituximab in combination with high-dose chemotherapy followed by autologous stem cell transplantation is a routine choice [31] yet, majority of patients experience poor outcome. High degree of genomic instability [32], distinct chromosomal alterations including losses, gains, and amplifications of chromosomal regions harboring gene(s) involved in cell-cycle regulation, DNA damage response pathways, signal transduction, and apoptosis are the major driving forces of MCL [1].

One of the stumbling blocks of treating MCL is accompanied by the deregulation of Bcl-2, Mcl-1 and BIM or inactivation of Apaf-1, thereby allowing these cells to evade caspase-mediated apoptosis [33, 34]. Higher expression of $\mathrm{Bcl}-2$ family antiapoptotic proteins assisted by cyclin D1 mis-expression, faulty ubiquitin-proteasome system and defects in apoptosis upstream of caspase activation, renders MCL more difficult to treat [35]. Therefore, exploiting small-molecule that can directly activate pro-casp3 obliterating upstream regulators would be a more rational approach for targeting MCL [36, 37].

Earlier observation on pet dog bearing lymphoma [15] documented that S-PAC-1 activated procaspase-3 and elicit tumor cell death (an earlier derivative of B-PAC-1). In this study authors performed a small efficacy trial with S-PAC-1, which included six pet dogs bearing lymphoma and showed that S-PAC-1 was well tolerated and that the treatments induced partial tumor regression in four of six subjects. Furthermore a recent study documented with a detailed antitumor activity of PAC-1 (an earlier derivative of B-PAC-1) in murine xenograft model [38] carrying EL4 lymphoma cells transplanted in C57BL/6 mice and were treated with PAC-1 (125 mg/kg), 1541B $(17.5 \mathrm{mg} / \mathrm{kg})$, or with a combination of PAC-1 and 1541B $(125 \mathrm{mg} / \mathrm{kg}$ and $17.5 \mathrm{mg} / \mathrm{kg}$, respectively) once-a-day for three days. While PAC-1 had a small but statistically significant effect on tumor growth in this model, the combination of PAC-1 and $1541 \mathrm{~B}$ dramatically retarded tumor growth in vivo without any systemic toxic side effects.

PAC-1 was synthesized to activate Casp3 by chelating inhibitory zinc ions from the zymogen proCasp3 initiating tumor cell death both in vitro and in vivo 
[14] and currently in Phase I clinical trial. B-PAC-1 was created [15] as an analogue of the first generation compound PAC-1. In this work, we test the efficacy of B-PAC-1 in MCL and present evidence showing B-PAC-1 has the ability to directly activate pro-casp3 to induce $\mathrm{PCD}$ in MCL cell lines via $\mathrm{Zn}$ sequestration and incubation of B-PAC-1 and $\mathrm{Zn}$ together significantly disrupt apoptotic program. We further show evidence that B-PAC-1 induces PCD in multiple primary lymphomas regardless of their cytogenetic status or their subtypes. Despite a variable magnitude of cell death offered by B-PAC-1 in the patient samples, consistent to our cell line studies we show that reversal of apoptosis via $\mathrm{Zn}$ chelation is widespread in primary lymphoma cells. However, normal $\mathrm{T}$ and $\mathrm{B}$ lymphocytes were less sensitive to B-PAC-1 mediated PCD providing a therapeutic index [39].

Despite a strong metal binding affinity exists in B-PAC-1 (containing the ortho-hydroxy $\mathrm{N}$-acyl hydrozone motif), however, the $\mathrm{Zn}$ chelation is not widespread with other apoptosis-inducing drugs (Figure 1H). B-PAC-1 mediated $\mathrm{Zn}$ chelation was specific to executioner pro-caspases since B-PAC-1 does not alter the $\mathrm{Zn}$-binding enzymes such as carboxypeptidase A or histone deacetylase [39]. Similarly, B-PAC-1 treatment did not influence inflammatory caspases like Casp1 [39] suggesting selectivity of B-PAC-1 for apoptotic terminal caspases.

Following a death stimuli, both intrinsic and the extrinsic apoptotic pathways converge and activate the "executioner" procaspases (pro-casp3, 7 and 6) through a cascade of events [40] leading to proteolysis of $>400$ cellular proteins. We therefore assessed the role of B-PAC-1 on executioner caspases mostly in their respective nucleophilic sites. While initiator caspase- 8 and -9 normally exist as inactive monomers that are activated by dimerization and not by cleavage [6] the effecter Casp3, 6 and 7 exist as dimers and are cleaved by initiator caspases leading to a conformational change that brings the two active sites together and creates a functional mature protease [41]. These procedural differences in the activation of initiator versus executioner caspases may result in selective action of B-PAC-1 on executioner caspases via $\mathrm{Zn}$ sequestration. Normally, Casp3 is a heterotetramer in its functional form and each heterodimer is formed and stabilized by hydrophobic interactions between the large (p17) and small (p12) subunits. The active site of Casp3 utilizes a cysteine-histidine dyad, with an aspartate in the $\mathrm{P} 1$ pocket. The active pocket of Casp3 is the nucleophilic cysteine163 and histidine121 [42]. Using DKO MEFs stably overexpressing Casp3-C163A or Casp7-C186A we show that B-PAC-1 failed to induce PCD reconfirming B-PAC-1 driven apoptosis requires catalytic cysteine moieties of both Casp3 and -7 regardless of $\mathrm{Zn}$ chelation for a full grown PCD.

Recently we documented B-PAC1 efficacy to induce apoptosis in both CLL and multiple myeloma cells
$[39,43]$, however the mechanism of $\mathrm{Zn}$ chelation is not known. We therefore interrogated where $\mathrm{Zn}$ is bound to procaspase 3 and how next generation PAC-1 compounds could be made more specific to caspase activation via $\mathrm{Zn}$ chelation. Historically, the role of $\mathrm{Zn}$ on apoptosis emerged from the pioneering study showing drastic PCD in the small intestinal crypts of zinc-deficient rats [44] or in leukemic cell lines [45] likely due to lack of zinc-mediated caspase inhibition. Essentially, glucocorticoid-induced PCD in mouse thymocytes was inhibited by $\mathrm{Zn}$ ions [46]. Although high zinc concentrations $(>500 \mu \mathrm{M})$ induce PCD but at physiological level zinc is known as suppressor of apoptosis [47]. The inhibition of caspases by $\mathrm{Zn}$ and other transition metals, including copper, was reported soon after the discovery of caspases [21]. Zn preferentially binds to Cys (5.8\%), His (2.4\%), Asp (0.28\%), and Glu (0.13\%) (CHDE), collectively account for $\sim 98 \%$ of all Zn-binding residues [48]. Although majority $(>90 \%)$ of cellular zinc is known to be sequestered in tightly-bound complexes of metalloenzymes and zinc finger proteins, however a small portion $(<10 \%)$ of zinc exists in labile, loosely-bound pools [49]. Amongst other executioner caspases, Zn binds to Lys-36, Glu-244 and His-287 with a water molecule serving as the fourth ligand in Casp6 [23]. Similarly, H237, C239, and C287 include the active site dyad and are primarily responsible for zinc-mediated inhibition in Casp9 [22].

While the active sites for $\mathrm{Zn}$ in Casp3 molecule is unknown, we used the exosite cluster analysis of Casp9 [22] and mutated several predicted $\mathrm{Zn}$-binding regions in both active and exosites. Our biochemical analysis shows that only E272 had an impact on apoptosis; while both $\mathrm{H} 108$ and $\mathrm{C} 148$ are not relevant sites since $\mathrm{Zn}$ could still significantly inhibit B-PAC-1-induced PCD in these mutants. Interestingly none of these clones were found to induce spontaneous apoptosis when over-expressed into DKO-MEF cells. In contrast, we encountered a unique mechanism of resistance to PCD from these mutant clones owing to relatively higher expression of XIAP and stronger Casp3-XIAP physical interaction rendering resistance to spontaneous apoptosis in these clones.

E272 is involved in several intra- and inter-domain interactions that may account for the observed effect (Figure 3C). Crystal structures of active Casp3 proposed multiple backbone-backbone interactions between the $\beta$-strands of the small subunits from residues 264-267 (Green $\beta$-strands in Figure 3C). Further, there are interdomain hydrogen bonds between the side chains of both E272 and E231 of one small subunit and H234 of the opposing small subunit. Within each small subunit, the side chain carboxyl group of E272 contacts the side chain hydroxyl group of Y274, and both residues contact $\beta$ and $\gamma$ methylene groups of E231, the initial amino acid in $\alpha$-helix 231-247. Additionally, the non-polar side chain atoms of E272 and Y274 in the small subunit contact the $\mathrm{BCH}_{2}$ of S36 in the large subunit. The carboxyl group of E272 is 
located within hydrogen bonding distance to H234 in the opposing small subunit in the dimeric unit. This network of interactions likely plays a role in stabilization of helix 231-247 and may be important for interaction with N-terminal segment of the large subunit. Replacement of E272 with alanine would remove the hydrogen bond with Y274 which could destabilize this cluster and alter the interactions between the large and small subunits of heterodimer. Further, disruption of this cluster could interrupt the interactions between the two small subunits thereby destabilizing the tetrameric structure of the enzyme complex which could alter the placement of the loop bundle [26] leading to impaired catalytic activity or altered substrate recognition. Further, the E272A mutation could alter the dynamics of helix 231-247 which could potentially impact catalytic activity in a manner analogous to the removal of zinc from the exosite in Casp6.

IAPs are unique molecules with BIR (baculovirus IAP repeat) domain and XIAP is the prototype member of the family. The complex structure of the Bir2 domain of XIAP and the catalytic domains of Casp3 indicates that the interaction takes place at the catalytic site and impact the loop bundle [25]. Given that the mutations in the exosites were rather distal from the catalytic site and from the sites of interaction of the Bir2 domain, it is not clear why the mutants would exhibit apparent increased affinity for XIAP. The mechanism by which these Casp3Zn mutants inhibit spontaneous apoptosis awaits further studies although earlier predictions have suggested that $\mathrm{H} 237$ and $\mathrm{C} 285$ are involved in catalysis [50], yet no work has been reported using these targets and to our knowledge this study is the first documentation of how Casp3- $\mathrm{Zn}$ interaction is destabilized following mutation in the predicted exosites of Casp6 and Casp9.

\section{MATERIALS AND METHODS}

\section{Cell lines and culture}

Three MCL cell lines (Granta-519, JeKo-1 and Mino) were used in this study. Granta-519 was maintained in Dulbecco modified Eagle medium with high glucose (DMEM, Cellgro) supplemented with 20\% FBS while both Jeko-1 and Mino cell lines were cultured in RPMI 1640 medium (ATCC) supplemented with 20\% FBS. Wild type, heterozygote and double knockout mouse embryonic fibroblasts for Casp3 and Casp7 (DKO $\mathrm{MEF}$ ) were maintained through passage 10 in DMEM (Cellgro) supplemented with 10\% FBS. All media were supplemented with $1 \%$ penicillin-streptomycin (Invitrogen Inc.). These cell lines were routinely tested for Mycoplasma using a MycoTect kit (Invitrogen). MCL cell lines were validated by AmpF/STR Identification kit (Applied Biosystems) in the MD Anderson cell line validation core facility. Routine cell number and the mean cell volume were determined by Coulter channelyzer (Coulter Electronics).

\section{Patients and primary cell culture}

For primary lymphomas, informed consent from every patient was obtained before inclusion in the study and was in accordance to the declaration of Helsinki. All protocols were approved by the Institutional Review Board at MD Anderson Cancer Center. Malignant lymphocytes from peripheral blood or from apheresis samples were isolated by Ficoll-Hypaque as described [17]. Cells were incubated in RPMI 1640 medium (ATCC) supplemented with $20 \%$ FBS and $1 \%$ penicillin-streptomycin.

\section{Reagents and antibodies}

B-PAC-1 and PAC-1a, were $>98 \%$ pure and were provided by Prof. PJ Hergenrother, University of Illinois $[14,16]$. Smac 066 was kindly provided by Dr. P. Seneci, University of Milan. All reagents and antibodies are listed in Supplementary Table $1 \mathrm{~S}$.

\section{Cloning and constructs}

Plasmids 11813 (pcDNA3-Casp3-myc); 11814 (pcDNA3-Casp3 C163A-myc); 11815 (pcDNA3-Casp7Flag); 11816 (pcDNA3-Casp7 C186A-Flag) and HAXIAP (plasmid 25674: pEBB-HA-hILP) were obtained from Addgene. For Casp3-Zn mutation plasmids, a WT Casp3 construct was generated by cloning a PCRamplified full-length human Casp3 coding region into EcoR1-BglII sites of p3XCMV-14 (Sigma) vector upstream of $\mathrm{C}$ terminal Flag epitope. Mutations in predicted Casp3-Zn binding amino acids were made by two-step PCR-based strategy. The following primers were used: 5'-GAAGATGCTAGCAAAAGGAGCAG-3' for generating Casp3 H108-A mutation; 5'-TTTTTCAGAGGGGATCGTAGTAGAAG-3'

for generating Casp3 C148S mutation while Casp3 E272A mutation was introduced into a common reverse complement that contained a BglII cloning site (5'-CGATATCAGATCTATTTAGTGATAAAAAT AGAGTGCTTTTGTGA-3'). Mutated nucleotides are underlined. Similar two step PCR strategy was employed to create double (H108A and C148S or C148S and E272A) or triple (H108A, C148S and E272A) mutants. All plasmids were sequence verified at MD Anderson DNA sequencing core facility and cloned into EcoR1-BglII sites of p3XCMV-14 (Sigma).

\section{Transfection}

DKO MEF cells were transfected overnight with 3 $\mu \mathrm{g}$ of p3X-CMV FLAG-Casp3 WT or Casp3-Zn mutant plasmids or with an empty vector control by using Lipofectamine 2000 (Invitrogen Inc). Forty eight hour 
after transfection, cells were selected in G418 (500 $\mu \mathrm{g} /$ $\mathrm{ml}$ ) containing medium for 3 weeks. Several independent colonies were isolated, expanded, and analyzed for protein expression. For transient co-transfection assay, HEK293 cells were transfected with $3 \mu$ g each HA-XIAP and p3X-CMV-FLAG Casp3 WT, Casp3-Zn-mutants or empty vector (p3X-CMV-FLAG plus pcDNA3.1) by using FuGENE6 (Promega Inc) transfection reagent. Forty eight hour after transfection cells were harvested for immunoprecipitation analysis.

\section{Immunoprecipitation and co-IP}

Sub-confluent stably over-expressed DKO MEF cells (in 100-mm plates) were lysed in IP buffer (Pierce) and an equal amount of lysates $(3000 \mu \mathrm{g})$ was immunoprecipitated overnight with EZview red anti-Flag ( $25 \mu \mathrm{l} / \mathrm{mg}$ protein) affinity gel. For co-IP assay, HEK-293 cells were transfected with $3 \mu \mathrm{g}$ each of HA-XIAP and p3XCMVFLAG-Casp3 WT or Casp3-Zn mutant plasmids. At 48 $\mathrm{hr}$ post-transfection, cells were lysed in IP buffer and an equal amount of lysates $(500 \mu \mathrm{g})$ was immunoprecipitated overnight with EZview red anti-Flag or EZview red antiHA affinity gel (Sigma). Following immunoprecipitation, the beads were washed 3 times with lysis buffer, resuspended in 2X Laemmli sample buffer (Bio-Rad Lab), fractionated on SDS-12\% polyacrylamide gel and analyzed by Western blot with rabbit anti-HA (Bethyl Lab, TX, USA) or with mouse M2-FLAG (Sigma) antibodies.

\section{Western blot analysis}

Protein lysates and immunoblots were prepared as described [18]. Protein band quantification was done using a LI-COR Odyssey CLx Infrared Imaging System.

\section{Total RNA extraction and real time PCR assay}

Total RNA from MEF cells was prepared [17] by using RNeasy Mini Kit (Qiagen, 74106) and quantitated using NanoDrop ND 1000 spectrophotometer (Thermo Fisher Scientific). Real time PCR was performed using 7900HT Fast Real-Time PCR detection system (Applied Biosystems). Primers and probes used for mRNA detection were as follow: CASP3 (Hs00234387 m1), XIAP (Mm01311594_mH), and GAPDH (Hs03929097_g1).

\section{Flow cytometry}

Briefly $10^{6}$ cells were stained with Annexin V FITC followed by propidium iodide staining and acquired on a FACS Calibur (BD Biosciences) and analyzed using Flow Jo software (TreeStar) as previously described [17].

\section{Immunofluorescence}

Jeko-1 cells were cyto-spinned on slides [18] following B-PAC-1 treatment. Cells were fixed in $2 \%$ paraformaldehyde, permeablized with $0.2 \%$ Triton X-100, and stained with cleaved anti-rabbit Casp3 antibody and with 1:100 diluted Hoechst stock solution in $\mathrm{H}_{2} \mathrm{O}$ using standard protocol. Cells were mounted with ProLong Gold Antifade (Life Technologies Inc) and scanned in a Labophot-2 fluorescence microscope (Nikon, Tokyo, Japan).

\section{Statistical analysis}

Statistical analysis was done using Prism (GraphPad Software, San Diego, CA). All numerical results are presented as means \pm SEM. The statistical significance of differences was analyzed using Student's $t$ - test (paired) or by Anova analysis.

\section{ACKNOWLEDGMENTS}

WT, +/- and KO MEFs for Casp3 and -7 were generous gift from Dr. Besim Ogretmen, The Medical University of South Carolina, Charleston, SC and MCL cell lines were a gift from Dr Hesham Amin, UT MD Anderson Cancer Center. Authors wish to thank Dr Paul Hergenrother for his intellectual suggestions and Rakesh Sharma in MD Anderson Lymphoma SPORE to process primary Lymphomas for analysis.

\section{CONFLICTS OF INTEREST}

VG received a Sponsored Research Agreement from Vanquish Oncology; other authors declare no competing financial interests.

\section{GRANT SUPPORT}

This work was supported in part by CLL PO1 CA81534, research agreement from Vanquish Oncology, and Alliance grant from CLL Global Research Foundation.

\section{Editorial note}

This paper has been accepted based in part on peerreview conducted by another journal and the authors' response and revisions as well as expedited peer-review in Oncotarget.

\section{REFERENCES}

1. Jares P, Colomer D and Campo E. Genetic and molecular pathogenesis of mantle cell lymphoma: perspectives for new targeted therapeutics. Nat Rev Cancer. 2007; 7:750-762.

2. Cecconi D, Zamo A, Bianchi E, Parisi A, Barbi S, Milli A, Rinalducci S, Rosenwald A, Hartmann E, Zolla L and Chilosi M. Signal transduction pathways of mantle cell lymphoma: a phosphoproteome-based study. Proteomics. 2008; 8:4495-4506. 
3. Dal Col J, Zancai P, Terrin L, Guidoboni M, Ponzoni M, Pavan A, Spina M, Bergamin S, Rizzo S, Tirelli U, De Rossi A, Doglioni C and Dolcetti R. Distinct functional significance of Akt and mTOR constitutive activation in mantle cell lymphoma. Blood. 2008; 111:5142-5151.

4. Rizzatti EG, Falcao RP, Panepucci RA, Proto-Siqueira R, Anselmo-Lima WT, Okamoto OK and Zago MA. Gene expression profiling of mantle cell lymphoma cells reveals aberrant expression of genes from the PI3K-AKT, WNT and TGFbeta signalling pathways. Br J Haematol. 2005; 130:516-526.

5. Jares P, Colomer D and Campo E. Molecular pathogenesis of mantle cell lymphoma. J Clin Invest. 2012; 122:3416-3423.

6. McIlwain DR, Berger T and Mak TW. Caspase functions in cell death and disease. Cold Spring Harb Perspect Biol. 2013; 5:a008656.

7. Fuentes-Prior P and Salvesen GS. The protein structures that shape caspase activity, specificity, activation and inhibition. Biochem J. 2004; 384:201-232.

8. Vassilev LT, Vu BT, Graves B, Carvajal D, Podlaski F, Filipovic Z, Kong N, Kammlott U, Lukacs C, Klein C, Fotouhi $\mathrm{N}$ and Liu EA. In vivo activation of the p53 pathway by small-molecule antagonists of MDM2. Science. 2004; 303:844-848.

9. Tovar C, Rosinski J, Filipovic Z, Higgins B, Kolinsky K, Hilton H, Zhao X, Vu BT, Qing W, Packman K, Myklebost O, Heimbrook DC and Vassilev LT. Small-molecule MDM2 antagonists reveal aberrant p53 signaling in cancer: implications for therapy. Proc Natl Acad Sci U S A. 2006; 103:1888-1893.

10. Oltersdorf T, Elmore SW, Shoemaker AR, Armstrong RC, Augeri DJ, Belli BA, Bruncko M, Deckwerth TL, Dinges J, Hajduk PJ, Joseph MK, Kitada S, Korsmeyer SJ, Kunzer AR, Letai A, Li C, et al. An inhibitor of Bcl-2 family proteins induces regression of solid tumours. Nature. 2005; 435:677-681.

11. Chen DJ and Huerta S. Smac mimetics as new cancer therapeutics. Anticancer Drugs. 2009; 20:646-658.

12. Putt KS, Chen GW, Pearson JM, Sandhorst JS, Hoagland MS, Kwon JT, Hwang SK, Jin H, Churchwell MI, Cho MH, Doerge DR, Helferich WG and Hergenrother PJ. Small-molecule activation of procaspase- 3 to caspase- 3 as a personalized anticancer strategy. Nat Chem Biol. 2006; 2:543-550.

13. Ghobrial IM, McCormick DJ, Kaufmann SH, Leontovich AA, Loegering DA, Dai NT, Krajnik KL, Stenson MJ, Melhem MF, Novak AJ, Ansell SM and Witzig TE. Proteomic analysis of mantle-cell lymphoma by protein microarray. Blood. 2005; 105:3722-3730.

14. Peterson QP, Goode DR, West DC, Ramsey KN, Lee JJ and Hergenrother PJ. PAC-1 activates procaspase- 3 in vitro through relief of zinc-mediated inhibition. J Mol Biol. 2009; 388:144-158.
15. Peterson QP, Hsu DC, Novotny CJ, West DC, Kim D, Schmit JM, Dirikolu L, Hergenrother PJ and Fan TM. Discovery and canine preclinical assessment of a nontoxic procaspase-3-activating compound. Cancer research. 2010; 70:7232-7241.

16. Hsu DC, Roth HS, West DC, Botham RC, Novotny CJ, Schmid SC and Hergenrother PJ. Parallel synthesis and biological evaluation of 837 analogues of procaspase-activating compound 1 (PAC-1). ACS Comb Sci. 2012; 14:44-50.

17. Balakrishnan K, Nimmanapalli R, Ravandi F, Keating MJ and Gandhi V. Forodesine, an inhibitor of purine nucleoside phosphorylase, induces apoptosis in chronic lymphocytic leukemia cells. Blood. 2006; 108:2392-2398.

18. Sarkar A, Zhang M, Liu SH, Sarkar S, Brunicardi FC, Berger DH and Belaguli NS. Serum response factor expression is enriched in pancreatic beta cells and regulates insulin gene expression. FASEB J. 2011; 25:2592-2603.

19. Amin HM, McDonnell TJ, Medeiros LJ, Rassidakis GZ, Leventaki V, O'Connor SL, Keating MJ and Lai R. Characterization of 4 mantle cell lymphoma cell lines. Arch Pathol Lab Med. 2003; 127:424-431.

20. Perry DK, Smyth MJ, Stennicke HR, Salvesen GS, Duriez P, Poirier GG and Hannun YA. Zinc is a potent inhibitor of the apoptotic protease, caspase-3. A novel target for zinc in the inhibition of apoptosis. J Biol Chem. 1997; 272:18530-18533.

21. Stennicke HR and Salvesen GS. Biochemical characteristics of caspases-3, -6, -7, and -8. J Biol Chem. 1997; 272:25719-25723.

22. Huber KL and Hardy JA. Mechanism of zinc-mediated inhibition of caspase-9. Protein Sci. 2012; 21:1056-1065.

23. Velazquez-Delgado EM and Hardy JA. Zinc-mediated allosteric inhibition of caspase-6. J Biol Chem. 2012; 287:36000-36011.

24. Rotonda J, Nicholson DW, Fazil KM, Gallant M, Gareau Y, Labelle M, Peterson EP, Rasper DM, Ruel R, Vaillancourt JP, Thornberry NA and Becker JW. The three-dimensional structure of apopain/CPP32, a key mediator of apoptosis. Nat Struct Biol. 1996; 3:619-625.

25. Riedl SJ, Renatus M, Schwarzenbacher R, Zhou Q, Sun C, Fesik SW, Liddington RC and Salvesen GS. Structural basis for the inhibition of caspase-3 by XIAP. Cell. 2001; 104:791-800.

26. Feeney B, Pop C, Swartz P, Mattos C and Clark AC. Role of loop bundle hydrogen bonds in the maturation and activity of (Pro)caspase-3. Biochemistry. 2006; 45:13249-13263.

27. Fernandez V, Hartmann E, Ott G, Campo E and Rosenwald A. Pathogenesis of mantle-cell lymphoma: all oncogenic roads lead to dysregulation of cell cycle and DNA damage response pathways. J Clin Oncol. 2005; 23:6364-6369.

28. Dreyling M, Amador V, Callanan M, Jerkeman M, Le Gouill S, Pott C, Rule S, Zaja F and for the European Mantle Cell Lymphoma N. Update on the molecular pathogenesis and targeted approaches of mantle cell lymphoma: 
summary of the 12th annual conference of the European Mantle Cell Lymphoma Network. Leuk Lymphoma. 2014:1-11.

29. Kridel R, Meissner B, Rogic S, Boyle M, Telenius A, Woolcock B, Gunawardana J, Jenkins C, Cochrane C, BenNeriah S, Tan K, Morin RD, Opat S, Sehn LH, Connors JM, Marra MA, et al. Whole transcriptome sequencing reveals recurrent NOTCH1 mutations in mantle cell lymphoma. Blood. 2012; 119:1963-1971.

30. Dawar R and Hernandez-Ilizaliturri F. The emerging role of lenalidomide in the management of mantle cell lymphoma (MCL). Best Pract Res Clin Haematol. 2012; 25:185-190.

31. Goy A and Kahl B. Mantle cell lymphoma: the promise of new treatment options. Crit Rev Oncol Hematol. 2011; 80:69-86.

32. Perez-Galan P, Dreyling M and Wiestner A. Mantle cell lymphoma: biology, pathogenesis, and the molecular basis of treatment in the genomic era. Blood. 2011; 117:26-38.

33. Yip KW and Reed JC. Bcl-2 family proteins and cancer. Oncogene. 2008; 27:6398-6406.

34. Soengas MS, Capodieci P, Polsky D, Mora J, Esteller M, Opitz-Araya X, McCombie R, Herman JG, Gerald WL, Lazebnik YA, Cordon-Cardo C and Lowe SW. Inactivation of the apoptosis effector Apaf-1 in malignant melanoma. Nature. 2001; 409:207-211.

35. Kuwana $\mathrm{T}$ and Newmeyer DD. Bcl-2-family proteins and the role of mitochondria in apoptosis. Curr Opin Cell Biol. 2003; 15:691-699.

36. Chelur DS and Chalfie M. Targeted cell killing by reconstituted caspases. Proc Natl Acad Sci U S A. 2007; 104:2283-2288.

37. Zorn JA and Wells JA. Turning enzymes ON with small molecules. Nat Chem Biol. 2010; 6:179-188.

38. Botham RC, Fan TM, Im I, Borst LB, Dirikolu L and Hergenrother PJ. Dual small-molecule targeting of procaspase-3 dramatically enhances zymogen activation and anticancer activity. Journal of the American Chemical Society. 2014; 136:1312-1319.

39. Patel V, Balakrishnan K, Keating MJ, Wierda WG and Gandhi V. Expression of executioner procaspases and their activation by a procaspase-activating compound in chronic lymphocytic leukemia cells. Blood. 2015; 125:1126-1136.
40. Timmer JC and Salvesen GS. Caspase substrates. Cell Death Differ. 2007; 14:66-72.

41. Riedl SJ and Shi Y. Molecular mechanisms of caspase regulation during apoptosis. Nat Rev Mol Cell Biol. 2004; 5:897-907.

42. Bose K, Pop C, Feeney B and Clark AC. An uncleavable procaspase- 3 mutant has a lower catalytic efficiency but an active site similar to that of mature caspase-3. Biochemistry. 2003; 42:12298-12310.

43. Zaman S, Wang R and Gandhi V. Targeting executioner procaspase-3 with the procaspase activating compound B-PAC-1 induces apoptosis in multiple myeloma cells. Exp Hematol. 2015; 43:951-962.e3.

44. Elmes ME. Apoptosis in the small intestine of zinc-deficient and fasted rats. J Pathol. 1977; 123:219-223.

45. Martin SJ, Mazdai G, Strain JJ, Cotter TG and Hannigan BM. Programmed cell death (apoptosis) in lymphoid and myeloid cell lines during zinc deficiency. Clin Exp Immunol. 1991; 83:338-343.

46. Duke RC, Chervenak R and Cohen JJ. Endogenous endonuclease-induced DNA fragmentation: an early event in cell-mediated cytolysis. Proc Natl Acad Sci U S A. 1983; 80:6361-6365.

47. Rudolf $\mathrm{E}$ and Cervinka M. Zinc pyrithione induces cellular stress signaling and apoptosis in Hep-2 cervical tumor cells: the role of mitochondria and lysosomes. Biometals. 2010; 23:339-354.

48. Chai F, Truong-Tran AQ, Ho LH and Zalewski PD. Regulation of caspase activation and apoptosis by cellular zinc fluxes and zinc deprivation: A review. Immunol Cell Biol. 1999; 77:272-278.

49. Truong-Tran AQ, Grosser D, Ruffin RE, Murgia C and Zalewski PD. Apoptosis in the normal and inflamed airway epithelium: role of zinc in epithelial protection and procaspase-3 regulation. Biochem Pharmacol. 2003; 66:1459-1468.

50. Walker NP, Talanian RV, Brady KD, Dang LC, Bump NJ, Ferenz CR, Franklin S, Ghayur T, Hackett MC, Hammill LD and et al. Crystal structure of the cysteine protease interleukin-1 beta-converting enzyme: a (p20/p10)2 homodimer. Cell. 1994; 78:343-352. 